\title{
Componeer: A New Innovation in Aesthetic Dentistry
}

\author{
MMR Howlader ${ }^{1 *}$, MAH Sheikh ${ }^{2}$, TA Zannat ${ }^{3}$ and AK Shaikh ${ }^{4}$ \\ ${ }^{1}$ Associate Professor, Department of Conservative Dentistry \& Endodontics, Bangabandhu Sheikh Mujib Medical University, Dhaka, Bangladesh \\ ${ }^{2}$ Classified Specialist in Conservative Dentistry \& Endodontist, Combined Military Hospital, Savar Cantt, Bangladesh \\ ${ }^{3}$ Dental Surgeon, University Dental College, Dhaka, Bangladesh
}

${ }^{4}$ Associate Professor, Department of Neurology, Bangabandhu Sheikh Mujib Medical University, Dhaka, Bangladesh

\author{
*Corresponding author: Dr Md Mujibur Rahman Howlader, Associate Professor, \\ Department of Conservative Dentistry \& Endodontics, Bangabandhu Sheikh Mujib \\ Medical University, Dhaka, Bangladesh.
}

Received Date: October 11, 2021

Published Date: November 05, 2021

\section{Summary}

Componeer is prefabricated composite veneer system. It is an emerging esthetic solution for the treatment of discoloured, fractured, or congenitally malformed teeth, which once required full coverage restorations. The purpose of this article is to report a case of esthetic problems of maxillary anterior teeth in a 22 years old girl with its management of a new, noble, minimally invasive procedure involving recently introduced esthetic material" Componeer".

Keywords: Componeer; Esthetic restoration; Veneer; Minimal tooth preparation

\section{Introduction}

Veneering anterior teeth is a well established technique, which was brought to Dentistry by Dr. Pincus as early as 1937. From the mid -1970s, boosted by the development of composites and adhesive techniques, various concepts emerged including direct composite restorations, prefabricated composite veneers and of course, individualized porcelain indirect veneers [1].

Componeers are manufactured from nanohybrid composite that ensures excellent homogeneity and stability of the enamel shells. The extremely thin veneer $(0.3 \mathrm{~mm})$ allows conservation of tooth structure. The micro-retentive inner surface ensures a last bond, therefore, conditioning of the veneer is not required, making it a milestone in veneers [2]. This Componeer treatment is operator friendly, minimally invasive and single appointment procedure. Enamel and dentin shades are selected with shade guide prior to isolation, ideally under daylight lamp. Since componeer is primarily bonded to enamel, only one layer of one coat bond adhesive is applied to componeer with brush. The composite is distributed on the tooth using special modeling instrument. The body composite is stiff enough to hold the componeers in place without the tendency for them to float away, which would happen if a flowable composite were used. The pacer is used for stress-free application of the componeer to its final position, cured, finished and polished. Multiple componeers can be also be placed at the same time, using strips of clear matrix for separation [3].

\section{Case Report}

A 22-years old girl reported to the dept. of Conservative Dentistry \& Endodontics, BSMMU, with a chief complain of yellowish and ugly looking of upper front teeth. On general examination, she was apparently healthy. There was no significant medical history. Intraoral examination revealed mildly discoloured maxillary incisor teeth with earlier filling (Figure 1). The pulp vitality diagnostic tests showed that all her teeth were vital with no abnormal mobility. Intraoral periapical radiograph was taken to exclude any pathological sign. The case was diagnosed as malformed maxillary anterior teeth with aesthetic problems.

The treatment procedure was explained and informed consent was taken from the patient after explanation of the possible risk of the treatment. The teeth surfaces were cleaned with pumice. Enamel and dentin shade was matched using shade guide under daylight. With the help of the contour guides, large size was selected. After profound anesthesia and proper isolation of the area, teeth were prepared minimally (Figure 2). 
The prefabricated veneers were customized using abrasive disks (Swiss Flex, Coltene) and tried in (Figure 3). One coat Bond was applied onto the inner surface of the componeer and left undisturbed without light curing. Teeth were etched with $35 \%$ phosphoric acid for 15 seconds (Figure 4) and rinsed, followed by the application of bonding agent for 15 seconds and dried. Thereafter, dentin composite shade was applied onto the tooth surface, while the enamel shade was applied on the inner surface of the componeer. One by one, the componeer were pressed onto the teeth surfaces using the placer instrument (Figure 5), beginning with the two central incisors. Each componeer was subsequently cured and after that alignment was checked and corrected (Figure 6). Then Finishing was done with flexible aluminum disks. A post operative picture was taken (Figure 7).

The patient was re-evaluated after 1 week, 3 months, 6 months and 1 year. The patient was happy with her esthetically treated teeth without any complain of sensitivity up to one year follow up (Figure 8).

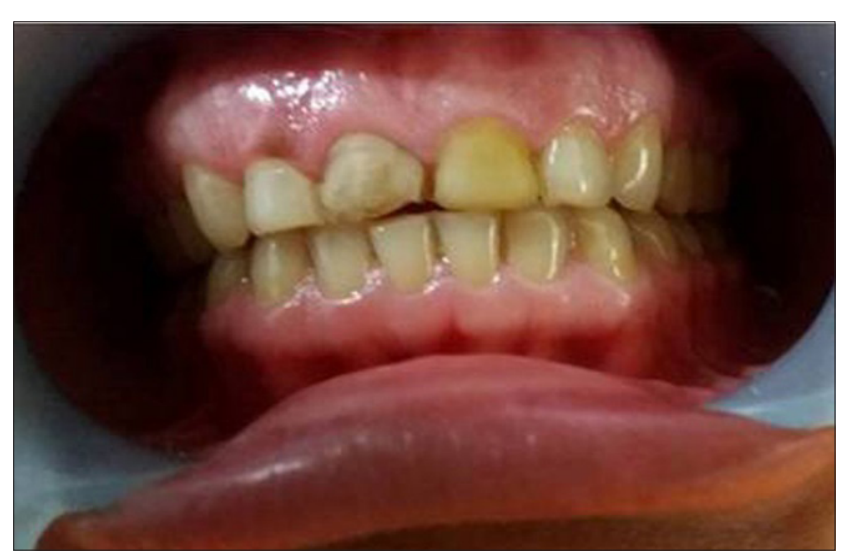

Figure 1: Initial Photograph.

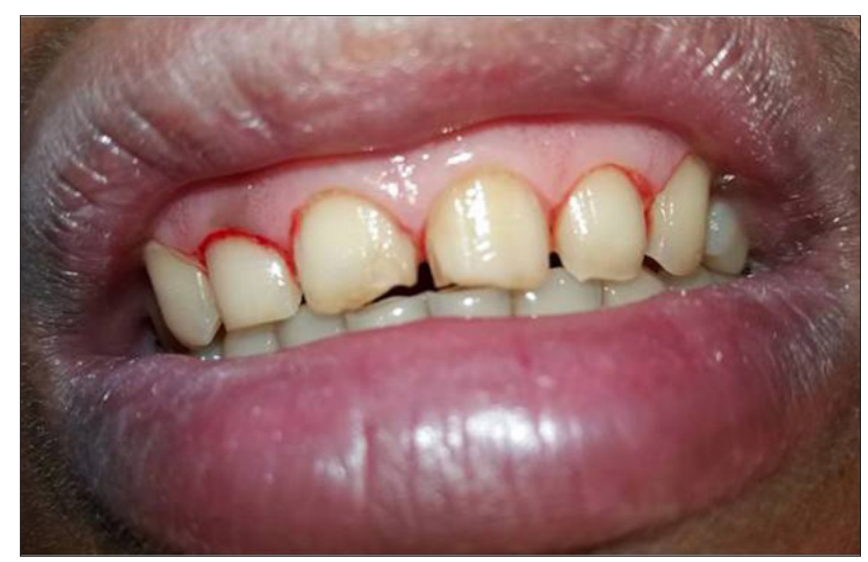

Figure 2: Minimal Tooth Preparation.

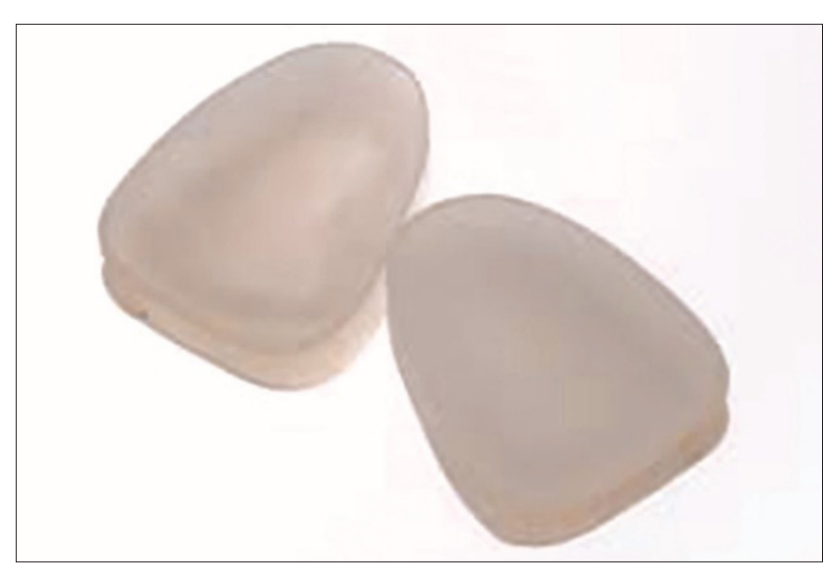

Figure 3: Componeer. 


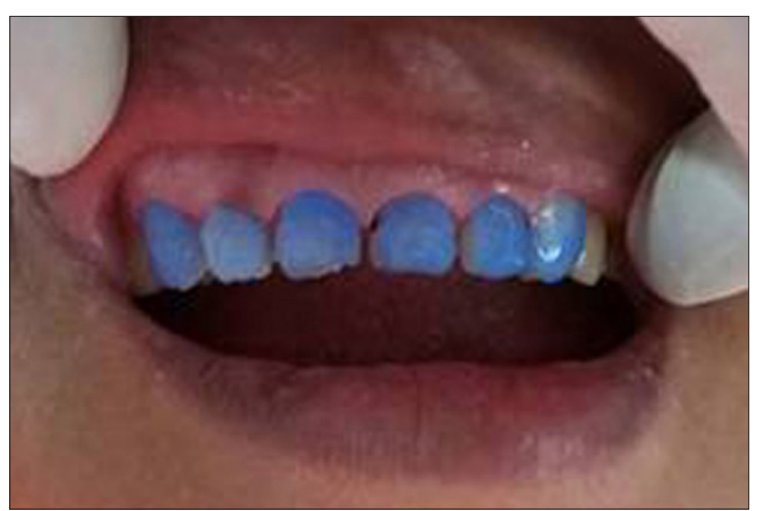

Figure 4: Etching of Teeth

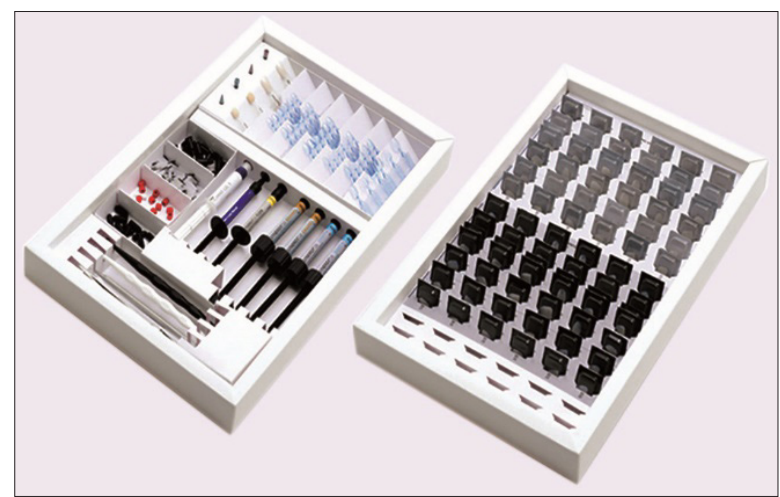

Figure 5: Componeer kit.

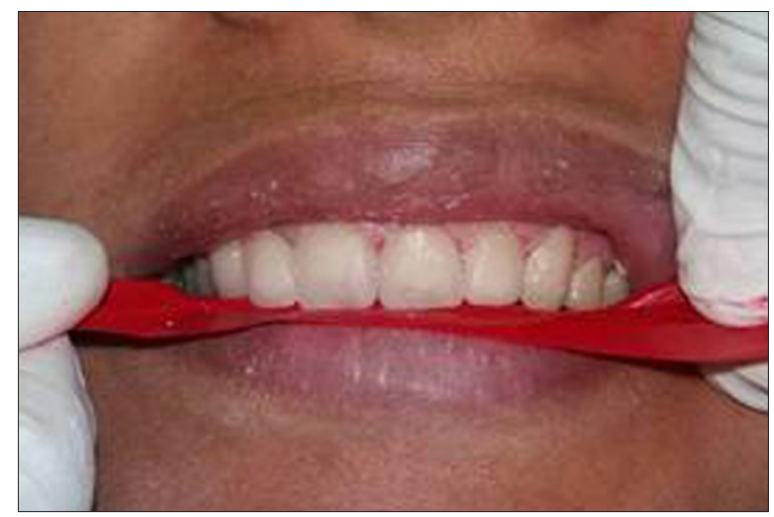

Figure 6: Occlusion check-up.

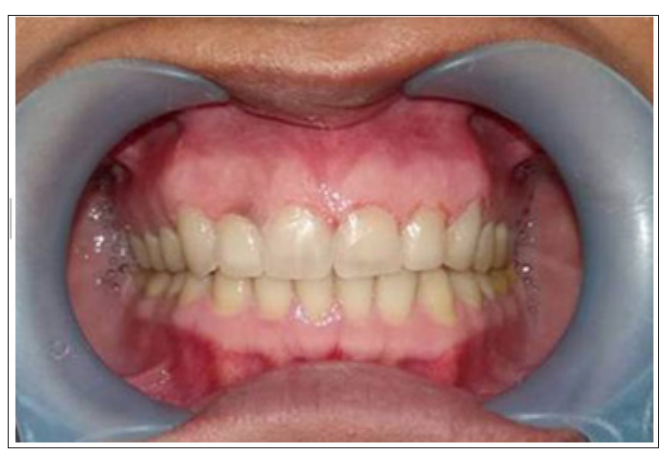

Figure 7: Final Esthetic. 


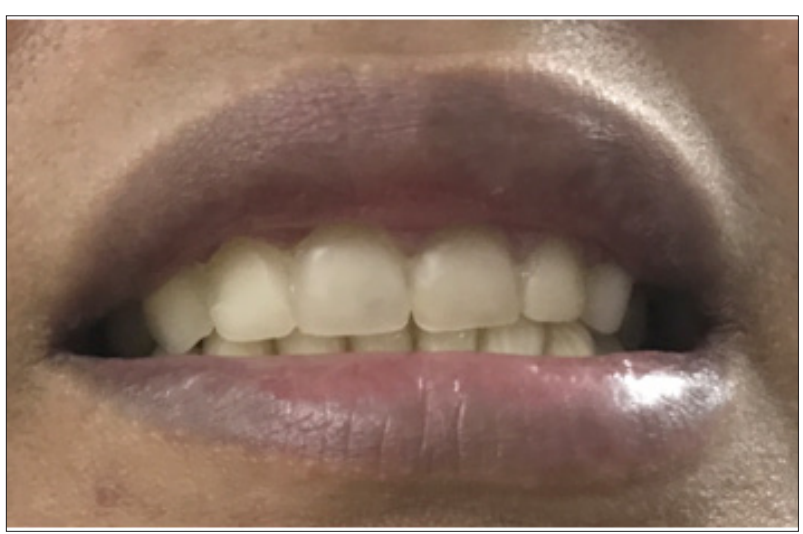

Figure 8: Follow up after one year.

\section{Discussion}

Designing a smile requires artistry and analysis. The subjective element of smile design may require years of experience for the dentist to develop the eye and talent for producing beautiful smiles. Direct composite additions with conventional hand layering technique or direct composite veneers have often been heralded as a more conservative alternative to porcelain, and with the advent of micro hybrid and nano-hybrid composites, the finishing and polishing of these restorations can rival that of porcelain [4]. Although they are found to be quick and economical, obtaining optimal results with direct composite restorations can provide a technical challenge in certain circumstances, particularly when treating multiple teeth [1]. In addition; wear-and-tear, degradation of the material over the course of time, loss of surface shine and cohesive cracks in the material, lack of strength and longevity needs desire for etched porcelain laminates offering benefits of increased strength, colour, stability, and biocompatibility for a veneering material using composite merely as a luting agent [5].

With componeer, quality esthetic restoration of anterior teeth can be performed efficiently in just a single session. Until now, the clinician could only choose between directly modeled composite restorations and elaborate veneer technology. The componeer adds a new and interesting dimension to existing treatment options and gives dentists and patients a new economic perspective. The preshaped componeer is available in various sizes ranging from small, medium, large to extra-large in sets of six. The unique transparent guides permit precise contour conformity and thus aids in the selection of the right tooth shape. The componeer provides optimum customization by careful grinding using abrasive disk to give an exact fit [6].

Componeer is fabricated from nanohybrid composite (Coltene, whaledent) and cemented using pure synergy composite, creating a monoblock restoration that provides enhanced fracture toughness, but simultaneously repairable. The compressive strength of enamel is $384 \mathrm{MPa}$, which is comparable to that of componeer, i.e., 392 $\mathrm{MPa}$. Componeer in this minimal preparation case acted mainly as an additive restorative material with high esthetic quality and adhesive strength, thereby minimizing retention failures $[2,7]$.
In this case report, the patient was explained all the possible treatment modalities, and a componeer was opted for the correction of esthetic problems. Ceramic veneers were ruled out as the patient was assertive on minimal tooth preparation. Direct composite veneering has a limitations of durability and colour stability with time.

\section{Conclusion}

Componeer represents a more conservative esthetic treatment modality which combines the superior esthetic property of cosmetic veneers, and the bond ability to tooth structure of composite veneers. These restorations can be customized, attractive and are more affordable than other indirect restorations resulting in an excellent long lasting esthetic outcome.

\section{Acknowledgment}

None.

\section{Conflict of Interest}

No conflict of interest.

\section{References}

1. Dietschi D, Devigus A (2011) Prefabicated composite veneers: Historical perspectives, indications and clinical application. Eur J Esthet Dent 6(2): 178-187.

2. Gomes G, Perdigao J (2014) Prefabicated composite resin veneers- A clinical review. J Esthet Restor Dent 26(5): 302-313.

3. Shinde TV, Dhage AS (2014) Componeers crowning glory of esthetic dentistry. Int J Dent Clinics 6(1): 10-11.

4. FahlJr N (1999) Achieving ultimate anterior esthetics with a new microhybrid composite. Compend Contin Educ Dent Suppl 26: 4-13.

5. Peumans M, Van Meerbeek B, Lambrechts P, Vanherle G (1971) The 5-year clinical performance of direct composite additions to correct tooth form and position. Clin Oral Investig 1(1): 12-18.

6. Gurtu A, Bansal R, Chowdhary P (2016) Componeer: An Emerging Esthetic Solution. J Dent Sci Oral Rehab 7(3): 146-148.

7. Perdigao J, Sezinando A, Munoz MA (2014) Prefabricated Veneers- Bond strengths and ultramorphological analyses. J Adhes Dent 16(2): 137146. 